\title{
Correspondence
}

\section{Immediate effects of albumin infusion in ill premature neonates}

Sir,

The paper on albumin infusion in neonates by Greenough et al gives us several reasons for concern. ${ }^{1}$ One issue, the lack of non-treated comparison infants, has been dealt with in the commentary. ${ }^{2}$ The weight loss in most preterm infants is, in our experience, independent of their degree of oedema and plasma albumin concentration, even in those sick with respiratory distress syndrome. We cannot agree, therefore, that it has been shown that albumin infusion caused the observed diuresis.

The authors have apparently measured urine passed in a number of discrete micturitions during a predetermined time interval, and have called this urine output. Bladder emptying is highly irregular, however, and variably incomplete in all sick preterm infants. We have observed micturition patterns in very low birthweight infants and have found the intermicturition interval to vary from less than one hour to more than 12 hours, and the volume passed from a few drops to $20 \mathrm{ml} / \mathrm{kg}$. Measurement of urine passed in an interval of six hours is therefore an inaccurate estimate of renal water excretion rate, especially when this is at a maximum of about $10 \mathrm{ml} / \mathrm{kg} / 6$ hours as stated, and most certainly when only 0.7 or $1.3 \mathrm{ml}$ is passed. In addition, parametric statistics have been used to compare these estimates of water excretion rates, which are highly unlikely to be normally distributed.

We are given urine output uncorrected for body size (water excretion rates in $\mathrm{ml} / \mathrm{kg} / \mathrm{day}$ would have been more helpful). Nevertheless prealbumin urine flow rates are low in all the infants studied (mean perhaps about $30 \mathrm{ml} / \mathrm{kg}$ / day). This is probably because water input in these infants was low; although this was not specified, it is implied that it remained around $40 \mathrm{ml} / \mathrm{kg} /$ day in the first few days. We give much larger volumes and only in exceptional cases is there an inability to excrete administered water, as has been found elsewhere in well babies. ${ }^{3}$ We dispute therefore the contention that the prolonged oedema and oliguria are necessarily due to failure of renal water homoeostatic mechanisms.

The study was designed to show whether albumin is effective in 'treating' hypoalbuminaemia. We find it hardly surprising that the rapid infusion of $20 \%$ albumin $(200 \mathrm{~g} / \mathrm{l})$ into a vascular space where the albumin is mean $27 \mathrm{~g} / 1$ raises the albumin concentration. The addition of $1 \mathrm{~g} / \mathrm{kg}$ of albumin into what is probably a vascular space of about $50 \mathrm{ml} / \mathrm{kg}$, however, raises the albumin concentration by only $5 \mathrm{~g} / \mathrm{l}$. This implies that an appreciable volume expansion has occurred, perhaps by as much as $50 \%$ if there really is no extravascular leak of the albumin. Such a volume expansion is likely to have caused an acute increase in glomerular filtration rate, which would have flooded the
Immature renal tubules with an increased filtered load, when reabsorptive capacity is already compromised. This will have resulted not only in the observed diuresis, but also in an acute loss of other solutes, especially sodium, where renal sodium conservation is already poor.

In summary, the authors do not give any evidence that a rapid albumin infusion does cause a diuresis, let alone that the resulting acute disturbance in vascular and renal physiology is beneficial. We believe that such a disturbance is more likely to be harmful and that, in the absence of convincing scientific support, this practice should not be promoted.

\section{References}

${ }^{1}$ Greenough A, Greenall F, Gamsu HR. Immediate effects of albumin infusion in ill premature neonates. Arch Dis Child 1988;63:307-8.

2 Rutter N. Commentary. Arch Dis Child 1988;63:309.

3 Coulthard MG, Hey EN. Effect of varying water intake on renal function in healthy premature babies. Arch Dis Child 1985;60:614-20.

B H Wilkins, T L Chambers, and P J Fleming Department of Child Health, Royal Hospital for Sick Children, St Michael's Hill, Bristol BS2 8BJ

\section{Dr Greenough comments:}

We thank Dr Wilkins et al for their interest in our short report on albumin infusion in the neonate. ${ }^{1}$ We have, however, already provided data within the report to answer their concerns. In summary: Dr Wilkins et al claim that, in their experience, weight loss and diuresis are independent of the degree of oedema and plasma albumin concentration, but unfortunately they do not present their data. In our study to document the effect of albumin infusion we measured both urine output and change in weight. Comparison of the control and treatment periods, during which no other changes were made, showed in eight of 10 infants urine output increased and all 10 infants lost weight after the infusion. As this response was seen in infants in varying stages of their respiratory illness the increase in urine output is likely to be associated with the albumin infusion.

We agree that the measurement of urine output in the preterm neonate is difficult. We therefore used the same method of urine collection during both periods, and in addition measured weight change. In the absence of change in fluid input and phototherapy status, changes in weight reflect changes in urine output. Using nonparametric statistics confirmed that both the increase in 